\title{
Formation of size-controllable spheroids using gingiva-derived stem cells and concave microwells: Morphology and viability tests
}

\author{
SUNG-IL LEE ${ }^{1}$, SEONG-IL YEO ${ }^{2}$, BO-BAE KIM ${ }^{1}$, YOUNGKYUNG KO ${ }^{1}$ and JUN-BEOM PARK ${ }^{1}$ \\ ${ }^{1}$ Department of Periodontics, College of Medicine, The Catholic University of Korea, \\ Seoul 06591; ${ }^{2}$ Prodizen Inc., Seoul 06100, Republic of Korea
}

Received August 6, 2015; Accepted September 18, 2015

DOI: $10.3892 /$ br.2015.539

\begin{abstract}
Human mesenchymal stem cells have previously been isolated and characterized from the gingiva, and gingiva-derived stem cells have been applied for tissue engineering purposes. The present study was performed to generate size-controllable stem cell spheroids using concave microwells. Gingiva-derived stem cells were isolated, and the stem cells of $1 \times 10^{5}$ (group A) or $2 \times 10^{5}$ (group B) cells were seeded in polydimethylsiloxane-based, concave micromolds with $600 \mu \mathrm{m}$ diameters. The morphology of the microspheres was viewed under an inverted microscope, and the changes in the diameter and cell viability were analyzed. The gingiva-derived stem cells formed spheroids in the concave microwells. The diameters of the spheroids were larger in group A compared to group B. No significant changes in shape or diameter were noted with increases in incubation time. Cell viability was higher in group B at each time point when compared with group A. Within the limits of the study, the size-controllable stem cell spheroids could be generated from gingival cells using microwells. The shape of the spheroids and their viability were clearly maintained during the experimental periods.
\end{abstract}

\section{Introduction}

Interest in stem cell research is increasing as mesenchymal stem cells provide an advantageous alternative therapeutic option for tissue regeneration $(1,2)$. The fates of stem cells, including survival, self-renewal and differentiation, are regulated by chemical and mechanical stimuli presented in their three-dimensional microenvironment (3). The majority of

Correspondence to: Dr Jun-Beom Park, Department of Periodontics, College of Medicine, The Catholic University of Korea, 222 Banpo-daero, Seocho-du, Seoul 06591, Republic of Korea E-mail: jbassoonis@yahoo.co.kr

Key words: cell culture techniques, cellular spheroids, stem cells, dimethylpolysiloxanes stem cell studies have been performed on two-dimensional substrates (3). Conventional stem cell culture methods do not enable the control of the microenvironment (4). A previous study used poly(ethylene glycol) microwells to produce easily retrievable cell aggregates with high viability and controlled sizes and shapes defined by the geometry of the microwells (5). Other materials, including polydimethylsiloxane and polyurethane, have been applied to create three-dimensional cultures using photolithography $(6,7)$. Additionally, poly(ethylene glycol) diacrylate, polymethylmethacrylate, poly(N-isopropylacrylamide) and polyester have been applied for the culture platform, while bypassing lithography (8-10). A previous study proved that three-dimensional culture systems have demonstrated the importance of intercellular interactions in regulating stem cell self-renewal and differentiation (3).

Human mesenchymal stem cells have previously been isolated and characterized from the gingiva (11), and gingiva-derived stem cells have been applied for tissue-engineering purposes (12). Thus, the present study was performed to generate size-controllable stem cell spheroids using concave microwells. To the best of our knowledge, this is the first study to create size-controllable spheroids using gingiva-derived stem cells.

\section{Materials and methods}

Isolation and culture of gingiva-derived stem cells. Gingival tissues were collected from healthy patients undergoing clinical crown-lengthening procedures. The design of the study was reviewed and approved by the Institutional Review Board of Seoul St. Mary's Hospital (College of Medicine, Catholic University of Korea, Seoul, Republic of Korea) (no. KC11SISI0348), and informed consent was obtained from the patients.

The gingival tissues were immediately placed in sterile phosphate-buffered saline (PBS; Welgene, Inc., Gyeongsan-si, Gyeongsangbuk-do, Korea) with $100 \mathrm{U} / \mathrm{ml}$ penicillin and $100 \mu \mathrm{g} / \mathrm{ml}$ streptomycin (Sigma-Aldrich Co., St. Louis, MO, USA) at $4^{\circ} \mathrm{C}$. The tissues were de-epithelialized, separated into $1-2 \mathrm{~mm}^{2}$ fragments, and digested in $0.2 \mu \mathrm{m}$ filtered, modified, minimal essential medium- $\alpha$ (Gibco, Thermo Fisher Scientific, Inc., Waltham, MA, USA) containing dispase 
( $1 \mathrm{mg} / \mathrm{ml}$; Sigma-Aldrich Co.) and collagenase IV (2 mg/ml; Sigma-Aldrich Co.). The cell suspension was filtered with a 70- $\mu \mathrm{m}$ cell strainer (Falcon, BD Biosciences, Franklin Lakes, NJ, USA), and the cells were incubated at $37^{\circ} \mathrm{C}$ in a humidified incubator with $5 \% \mathrm{CO}_{2}$. After $24 \mathrm{~h}$, the non-adherent cells were washed with PBS, replaced with fresh medium every 2-3 days.

Formation of spheres. Polydimethylsiloxane-based concave micromolds (Prosys ${ }^{\circledR}$ StemFit 3D; Prodizen Inc., Seoul, Korea) with $600 \mu \mathrm{m}$ diameters were generated using soft lithography techniques (Fig. 1). Spheroids were formed in the concave microwells. Subsequently, $1 \times 10^{5}$ (group A) or $2 \times 10^{5}$ (group B) stem cells/concave micromold were seeded and subsequently cultured for $\leq 8$ days to investigate the cellular behavior.

Evaluation of cellular morphology. The morphology of the microspheres was viewed under an inverted microscope (Leica DM IRM; Leica Microsystems, Wetzlar, Germany) on days 1, 2, 3, 4, 5 and 6 . The images were saved as JPEGs.

Determination of cell viability. A cell viability analysis was performed on days 1, 3 and 8. 2-(2-Methoxy-4-nitrophenyl)-3(4-nitrophenyl)-5-(2,4-disulfophenyl)-2H tetrazolium, monosodium salt (WST-8) [Cell Counting kit-8 (CCK-8); Dojindo, Tokyo, Japan] was added to the cultures, and the spheres were incubated for $1 \mathrm{~h}$ at $37^{\circ} \mathrm{C}$. Viable cells were identified using a CCK-8 assay, which relies on the ability of mitochondrial

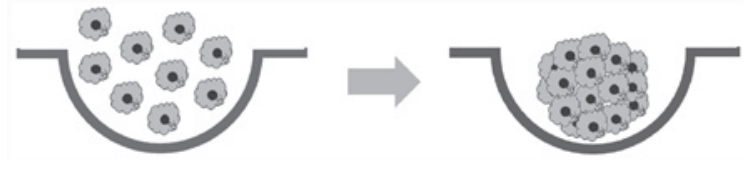

Figure 1. Schematic illustration of the spheroid fabrication using gingival-derived stem cells.

dehydrogenases to oxidize WST-8 into a formazan product. The spectrophotometric absorbance of the samples at $450 \mathrm{~nm}$ was measured using a microplate reader (BioTek, Winooski, VT, USA).

Statistical analysis. The data are represented as mean \pm standard deviation of the experiments. A test of normality was performed, and a Student's t-test or a two-way analysis of variance with post hoc test was performed to determine the differences between the groups using a commercially available program (SPSS 12 for Windows; SPSS Inc., Chicago, IL, USA). $\mathrm{P}<0.05$ was considered to indicate a statistically significant difference.

\section{Results}

Evaluation of cell morphology. Gingiva-derived stem cells formed spheroids in concave microwells. The morphology of the spheroids at day 1 is shown in Fig. 2A and B. The morphology
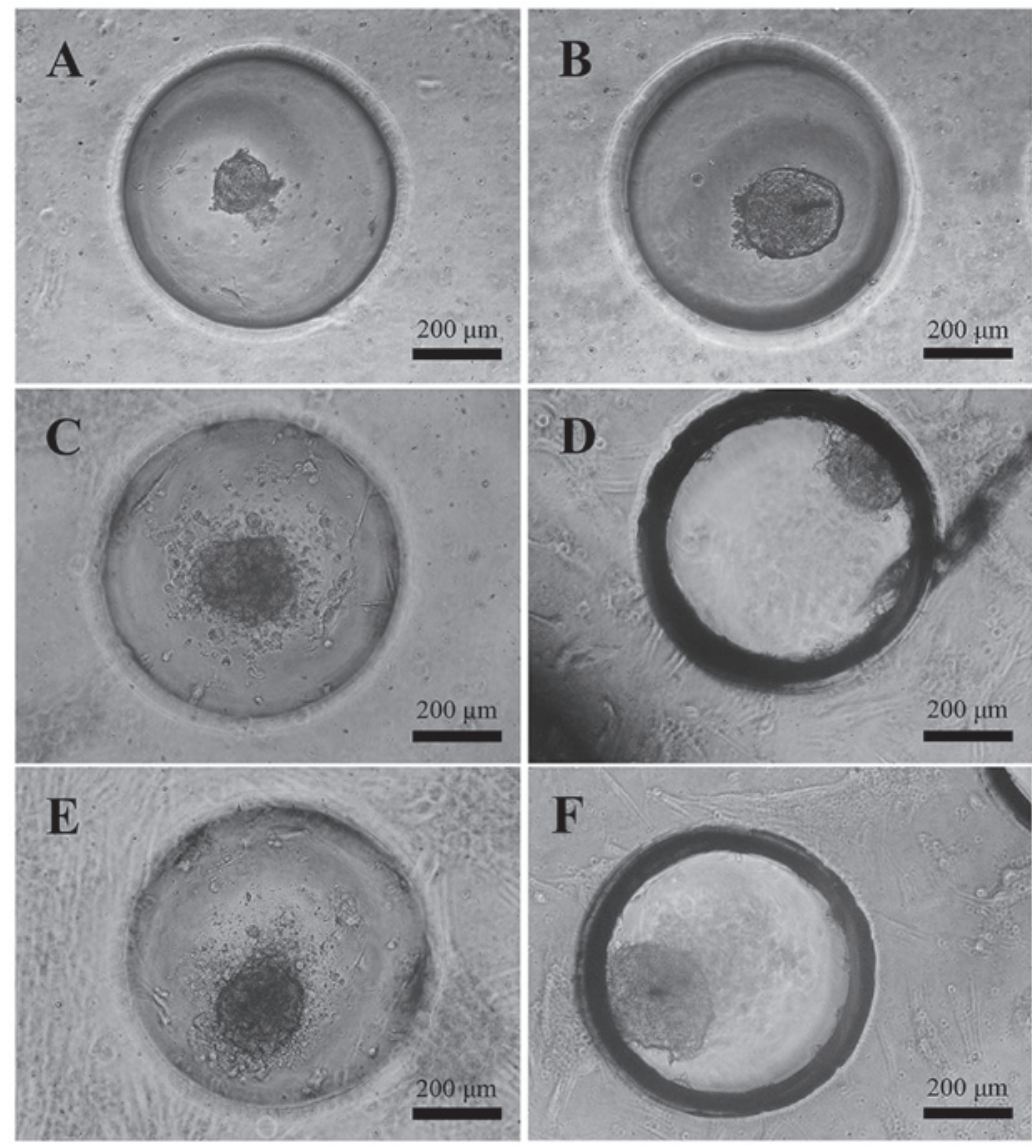

Figure 2. Morphology of the stem cell spheroids at days 1, 2 and 3. Group A at days (A) 1, (C) 2 and (E) 3 (original magnification, x150). Group B at days (B) 1, (D) 2 and (F) 3 (original magnification, x150). The scale bar indicates $200 \mu \mathrm{m}$. 


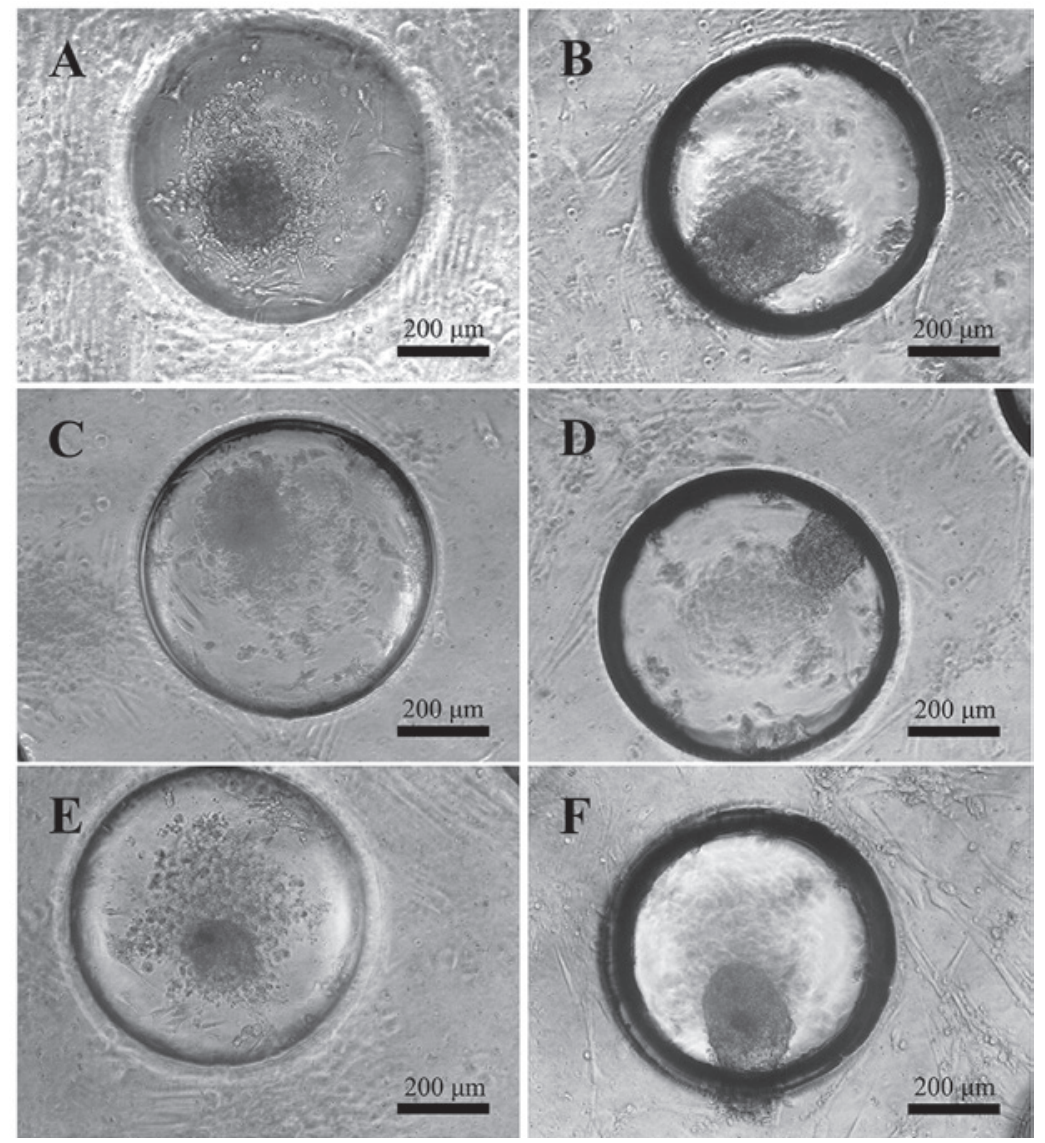

Figure 3. Morphology of the stem cell spheroids at days 4, 5 and 6. Group A at days (A) 4, (C) 5 and (E) 6 (original magnification, x150). (B) Group B at days (B) 4, (C) 5 and (E) 6 (original magnification, x150). The scale bar indicates $200 \mu \mathrm{m}$.

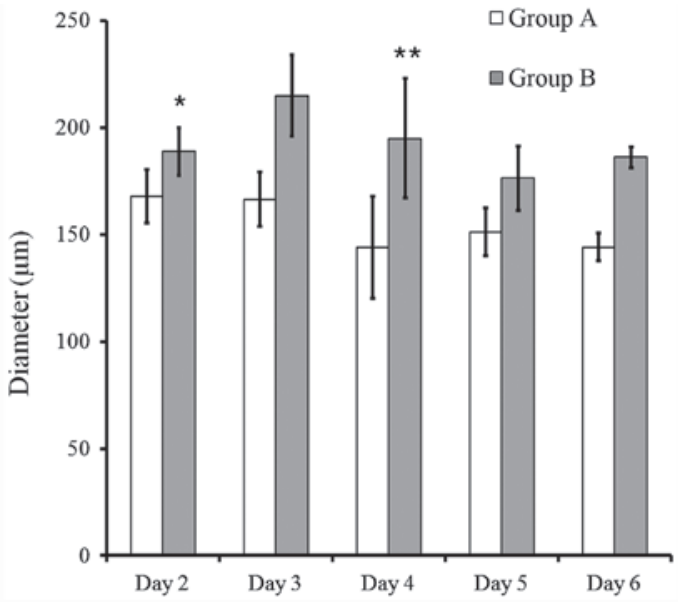

Figure 4. Spheroid diameter changes. Statistically significant differences were noted between groups $\mathrm{A}$ and $\mathrm{B}$ at days $1^{*}$ and $3^{* *}$.

of the spheroids at days 2 and 3 were similar to that of day 1 (Fig. 2C-F). No significant changes were noted with the longer incubation time (Fig. 3). The diameters of the spheroids were larger in group A, compared to those of group B. The average spheroid diameters in group A were 142.7 $\pm 11.1,167.8 \pm 12.6$, $166.4 \pm 12.8,144.1 \pm 23.9,151.0 \pm 11.1$ and $144.1 \pm 6.4 \mu \mathrm{m}$ for days 1-6, respectively (Fig. 4). The average spheroid diameters in group B were $200.0 \pm 8.7,188.8 \pm 11.1,214.8 \pm 18.9,194.8 \pm 27.9$, $176.2 \pm 15.1$ and $186.0 \pm 4.8 \mu \mathrm{m}$ for days $1-6$, respectively. The

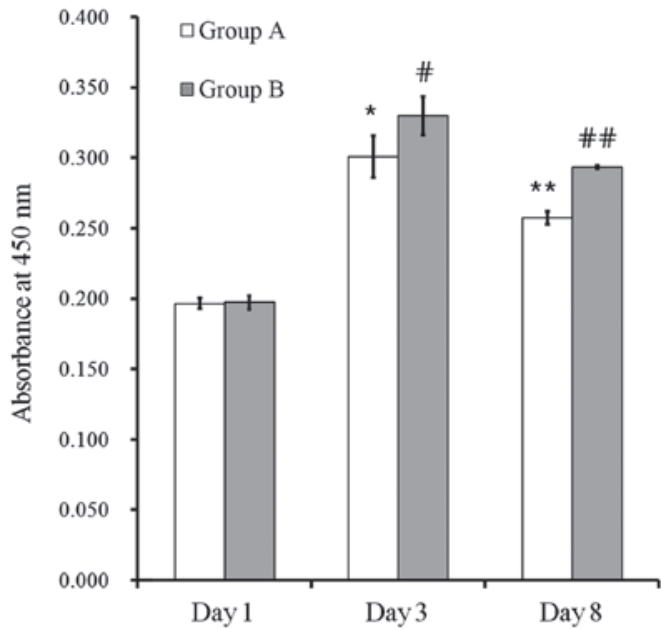

Figure 5. Cellular viability on days 1,3 and 8 . Statistically significant differences were noted when compared with groups $\mathrm{A}^{*, * * *}$ and $\mathrm{B}^{\#, \# \#}$ at day 1 .

diameters of the spheroids were maintained throughout the incubation time without statistically significant differences $(\mathrm{P}>0.05)$.

Cell viability. Cell viability was measured in the spheres made from polydimethylsiloxane-based concave micromolds after culturing at days 1,3 and 8 (Fig. 5). The cell viability in group B was higher compared to group A at each 
time point, although there were no statistically significant differences $(\mathrm{P}>0.05)$. The relative $\mathrm{CCK}-8$ assay values of groups $\mathrm{A}$ and $\mathrm{B}$ at day 3 were $153.1 \pm 7.6$ and $167.8 \pm 6.8 \%$, respectively, assuming that the $\mathrm{CCK}-8$ result of group A on day 1 was considered $100 \%(100.0 \pm 1.8 \%)$. The relative CCK- 8 assay values of groups A and B at day 8 were $130.8 \pm 2.3$ and $149.2 \pm 0.6 \%$, respectively, assuming that the CCK- 8 result of group A on day 1 was considered $100 \%$ (100.0 $\pm 1.8 \%)$. The relative viability of groups $\mathrm{A}$ and $\mathrm{B}$ at day 8 were $85.5 \pm 1.5$ and $88.9 \pm 0.3 \%$, when compared with the viability of each group at day 3 .

\section{Discussion}

In the present study, size-controllable stem cell spheroids were generated using microwells. The study clearly showed that the shape of the spheroids and their viability were maintained during the experimental periods.

To the best of our knowledge, this is the first study to apply gingiva-derived stem cells to three-dimensional spheroids. Stem cells can be obtained intraorally, including from the maxilla and mandible; this was suggested as a treatment option in tissue-engineering fields $(13,14)$. The gingiva, periosteum and bone marrow from the maxillofacial region are considered favorable sources of stem cells, as stem cells can be harvested from the jaw bone under local anesthesia $(13,15)$. Additionally, stem cells may be obtained intraorally, including from dental pulp and the periodontal ligament, but only a limited number of times; however, the gingiva is an easily accessible tissue source with wider availability (16).

In the present study, the size of the spheroids were controlled by the number of cells loaded initially, and their morphology was controlled by the shape of the well (5). The shape of the microwell can be modified into different shapes, including rectangles and triangles (3). Various cell types have been applied to microwells, including embryonic stem cells, islet cells and hepatocytes $(5,17,18)$. A previous study suggested that size may be an important parameter that influences cell differentiation (19).

Various methods may be applied to evaluate the viability of the spheroids. A protein assay may be considered an indirect measurement of cell viability, as it measures the protein content of cells, regardless of cell death (20). The trypan blue assay may be applied as the assay is based on the principle that live cells possess intact cell membranes that prevent penetration of the dye (21). The MTT assay may be more sensitive for assessing stem cell viability as it measures viability by determining mitochondrial dehydrogenase activity $(22,23)$. However, further treatment is required to solubilize formazan crystals, and the MTT agent may be toxic to cells (23). Thus, a cell counting kit utilizing a water-soluble tetrazolium salt test was applied for the viability test as it is reported to be more sensitive than the MTT assay and less toxic to the tested cells $(23,24)$.

The three-dimensional culture system for cell differentiation and proliferation may improve the current understanding of the structure-function association under normal and pathological conditions (25). It was reported that the three-dimensional behaviors of stem cells were different from the two-dimensional behaviors and that the three-dimensional system simulates the real situation more closely (26). Additionally, a three-dimensional spheroid system may be applied as a tool for skeletal tissue regeneration (27).

The co-culture method may be applied for enhanced functionality. Single primary islet cells have been co-cultured with adipose-derived stem cells in concave microwells, resulting in improved viability and function $(17,18,28)$. Stem cells may have significant potential to protect primary cells from damage during culturing and may be employed to improve cell survival and function prior to transplantation (17). Another study used primary pancreatic islets and hepatocytes for the three-dimensional co-culture model, and these two types of cells appeared to strongly support the functions of each other as spheroids, even though smaller proportions of each cell type were evaluated when compared to the mono-culture models (18). Size-controllable spheroids with primary hepatocytes and hepatic stellate cells secreted more albumin compared to the mono-culture hepatospheres, and the enzymatic activity of co-cultured heterospheres was higher compared to that of a mono-culture of hepatospheres (28).

Within the limits of the present study, size-controllable stem cell spheroids were generated from gingival cells using microwells. The shape of the spheroids and the viability were clearly maintained during the experimental periods.

\section{Acknowledgements}

The present study was supported by the Basic Science Research Program through the National Research Foundation of Korea (NRF) funded by the Ministry of Science, Information and Communication Technology and Future Planning (grant no. NRF-2014R1A1A1003106).

\section{References}

1. Moshaverinia A, Chen C, Xu X, Akiyama K, Ansari S, Zadeh HH and Shi S: Bone regeneration potential of stem cells derived from periodontal ligament or gingival tissue sources encapsulated in RGD-modified alginate scaffold. Tissue Eng Part A 20: 611-621, 2014.

2. Jeong SH, Kim BB, Lee JE, Ko Y and Park JB: Evaluation of the effects of Angelicae dahuricae radix on the morphology and viability of mesenchymal stem cells. Mol Med Rep 12: 1556-1560, 2015.

3. Hsiao $\mathrm{C}$ and Palecek SP: Microwell regulation of pluripotent stem cell self-renewal and differentiation. Bionanoscience 2: 266-276, 2012.

4. Choi YY, Chung BG, Lee DH, Khademhosseini A, Kim JH and Lee SH: Controlled-size embryoid body formation in concave microwell arrays. Biomaterials 31: 4296-4303, 2010.

5. Karp JM, Yeh J, Eng G, Fukuda J, Blumling J, Suh KY, Cheng J, Mahdavi A, Borenstein J, Langer R, et al: Controlling size, shape and homogeneity of embryoid bodies using poly(ethylene glycol) microwells. Lab Chip 7: 786-794, 2007.

6. Mohr JC, de Pablo JJ and Palecek SP: 3-D microwell culture of human embryonic stem cells. Biomaterials 27: 6032-6042, 2006.

7. Khademhosseini A, Ferreira L, Blumling J III, Yeh J, Karp JM, Fukuda J and Langer R: Co-culture of human embryonic stem cells with murine embryonic fibroblasts on microwell-patterned substrates. Biomaterials 27: 5968-5977, 2006.

8. Kang L, Hancock MJ, Brigham MD and Khademhosseini A: Cell confinement in patterned nanoliter droplets in a microwell array by wiping. J Biomed Mater Res A 93: 547-557, 2010.

9. Sakai Y, Yoshida S, Yoshiura Y, Mori R, Tamura T, Yahiro K, Mori H, Kanemura Y, Yamasaki M and Nakazawa K: Effect of microwell chip structure on cell microsphere production of various animal cells. J Biosci Bioeng 110: 223-229, 2010. 
10. Selimović S, Piraino F, Bae H, Rasponi M, Redaelli A and Khademhosseini A: Microfabricated polyester conical microwells for cell culture applications. Lab Chip 11: 2325-2332, 2011.

11. Jin SH, Lee JE, Yun JH, Kim I, Ko Y and Park JB: Isolation and characterization of human mesenchymal stem cells from gingival connective tissue. J Periodontal Res 50: 461-467, 2015.

12. Jin SH, Kweon H, Park JB and Kim CH: The effects of tetracycline-loaded silk fibroin membrane on proliferation and osteogenic potential of mesenchymal stem cells. J Surg Res 192: e1-e9, 2014.

13. Park JB, Bae SS, Lee PW, Lee W, Park Y-H, Kim H, Lee KH and Kim IS: Comparison of stem cells derived from periosteum and bone marrow of jaw bone and long bone in rabbit models. Tissue Eng Regen Med 9: 224-230, 2012.

14. Park JB, Lee KS, Lee W, Kim HS, Lee KH and Kim IS Establishment of the chronic bone defect model in experimental model mandible and evaluation of the efficacy of the mesenchymal stem cells in enhancing bone regeneration. Tissue Eng Regen Med 10: 18-24, 2013.

15. Park JB, Lee G, Yun BG, Kim CH and Ko Y: Comparative effects of chlorhexidine and essential oils containing mouth rinse on stem cells cultured on a titanium surface. Mol Med Rep 9: $1249-1253,2014$

16. Zhang Q, Shi S, Liu Y, Uyanne J, Shi Y, Shi S and Le AD: Mesenchymal stem cells derived from human gingiva are capable of immunomodulatory functions and ameliorate inflammation-related tissue destruction in experimental colitis. J Immunol 183: 7787-7798, 2009.

17. Jun Y, Kang AR, Lee JS, Park SJ, Lee DY, Moon SH and Lee SH: Microchip-based engineering of super-pancreatic islets supported by adipose-derived stem cells. Biomaterials 35: 4815-4826, 2014.

18. Jun Y, Kang AR, Lee JS, Jeong GS, Ju J, Lee DY and Lee SH 3D co-culturing model of primary pancreatic islets and hepatocytes in hybrid spheroid to overcome pancreatic cell shortage. Biomaterials 34: 3784-3794, 2013.
19. Hwang YS, Chung BG, Ortmann D, Hattori N, Moeller HC and Khademhosseini A: Microwell-mediated control of embryoid body size regulates embryonic stem cell fate via differential expression of WNT5a and WNT11. Proc Natl Acad Sci USA 106: 16978-16983, 2009.

20. Fotakis $\mathrm{G}$ and Timbrell JA: In vitro cytotoxicity assays: Comparison of LDH, neutral red, MTT and protein assay in hepatoma cell lines following exposure to cadmium chloride. Toxicol Lett 160: 171-177, 2006.

21. Altman SA, Randers L and Rao G: Comparison of trypan blue dye exclusion and fluorometric assays for mammalian cell viability determinations. Biotechnol Prog 9: 671-674, 1993.

22. Park JB: Effects of doxycycline, minocycline and tetracycline on cell proliferation, differentiation and protein expression in osteoprecursor cells. J Craniofac Surg 22: 1839-1842, 2011.

23. Almazin SM, Dziak R, Andreana S and Ciancio SG: The effect of doxycycline hyclate, chlorhexidine gluconate, and minocycline hydrochloride on osteoblastic proliferation and differentiation in vitro. J Periodontol 80: 999-1005, 2009.

24. Jue SS, Lee WY, Kwon YD, Kim YR, Pae A and Lee B: The effects of enamel matrix derivative on the proliferation and differentiation of human mesenchymal stem cells. Clin Oral Implants Res 21: 741-746, 2010

25. Seo $\mathrm{S}$ and $\mathrm{Na} \mathrm{K}$ : Mesenchymal stem cell-based tissue engineering for chondrogenesis. J Biomed Biotechnol 2011: 806891, 2011

26. Valarmathi MT, Yost MJ, Goodwin RL and Potts JD: The influence of proepicardial cells on the osteogenic potential of marrow stromal cells in a three-dimensional tubular scaffold. Biomaterials 29: 2203-2216, 2008.

27. Occhetta P, Centola M, Tonnarelli B, Redaelli A, Martin I and Rasponi M: High-throughput microfluidic platform for 3D cultures of mesenchymal stem cells, towards engineering developmental processes. Sci Rep 5: 10288, 2015.

28. Wong SF, No Y, Choi YY, Kim DS, Chung BG and Lee SH: Concave microwell based size-controllable hepatosphere as a three-dimensional liver tissue model. Biomaterials 32: 8087-8096, 2011. 